\title{
A Teoria das Representações Sociais como referencial teórico-metodológico na pesquisa em Geografia: análise de teses e dissertações presentes na Capes de 2012 a 2016
}

The Theory of Social Representations as a theoretical-methodological reference in research in Geography: analysis of theses and dissertations present in the Capes from 2012 to 2016

La Teoría de las Representaciones Sociales como referencial teórico metodológico en la pesquisa de Geografía: análisis de tesis y disertaciones presentes en la Capes 2012 a 2016

Solange Franci Raimundo Yaegashi ${ }^{1}$

Bethânia Vernaschi de Oliveira ${ }^{1}$ Lucilia Vernaschi de Oliveira ${ }^{1}$

DOI: http://dx.doi.org/10.20435/serie-estudos.v24i50.1131

\begin{abstract}
Resumo: A Teoria das Representações Sociais (TRS) foi idealizada por Serge Moscovici no início da década de 1960 e tem sido utilizada em diferentes áreas do conhecimento para investigar como são produzidos, organizam-se e são veiculados os saberes sociais, utilizados para interpretar a realidade concreta na inter-relação dos grupos sociais. A presente pesquisa tem como objetivo analisar o uso da TRS como referencial teórico-metodológico para o ensino da Geografia na educação básica. Para a realização deste trabalho, selecionamos pesquisas stricto sensu cadastradas no banco de teses e dissertações na Coordenação de Aperfeiçoamento de Pessoal e Nível Superior (CAPES), no período de 2012 a 2016. Analisamos quatro teses e 25 dissertações, para isso organizamos dois quadros e um gráfico nos quais distribuímos informações relevantes do material analisado. Além disso, organizamos semanticamente, as 29 pesquisas em cinco categorias de análise. Os resultados apontam que a TRS tem sido um importante referencial teórico-metodológico para compreender fenômenos da Geografia e das diversas implicações que envolvem essa disciplina escolar.
\end{abstract}

${ }^{1}$ Universidade Estadual de Maringá (UEM), Maringá, Paraná, Brasil. 
Palavras-chave: representações sociais; teses e dissertações; ensino da Geografia.

Abstract: The Social Representation Theory (SRT) was conceived by Serge Moscovici in the early 1960s and has been used in different areas of knowledge to investigate how social knowledge is produced, organized and used to interpret reality in the interrelation of social groups. The present research aims to analyze the use of SRT as a theoretical-methodological reference for the teaching of Geography in basic education. To carry out this work, we selected stricto sensu researches registered in the theses and dissertations database in the Coordenação de Aperfeiçoamento de Pessoal e Nível Superior (CAPES), from 2012 to 2016. We analyzed four theses and 25 dissertations, for this we organized two tables and one graph in which we distribute relevant information of the analyzed material. In addition, we organized semantically the 29 surveys into five categories of analysis. The results indicate that the SRT has been an important theoretical-methodological reference to understand phenomena of Geography and the diverse implications that involve this school subject.

Keywords: social representations; theses and dissertations; teaching Geography.

Resumen: La Teoría de las Representaciones Sociales (TRS) fue idealizada por Serge Moscovici en el inicio de los años 1960 y se ha utilizado en diferentes áreas de conocimiento para investigar cómo son producidos, organizados y son transmitidos los saberes sociales utilizados para interpretar la realidad concreta en la interrelación de los grupos sociales. La presente pesquisa tiene como objetivo analizar el uso de TRS como referencial teórico metodológico para la enseñanza de la Geografía en la educación básica. Para la realización de este trabajo hemos seleccionado pesquisa stricto sensu registradas en el banco de tesis y disertaciones en la Coordinación de Perfeccionamiento de Personal y Nivel Superior (CAPES), durante el período 2012 a 2016. Se revisaron cuatro tesis y 25 disertaciones, para eso fueran organizadas en dos cuadros y un gráfico en los cuales distribuimos informaciones relevantes del material analizado. Además, hemos organizado semánticamente, las 29 pesquisas en cinco categorías de análisis. Los resultados apuntan que la TRS ha sido un importante referencial teórico metodológico para comprender fenómenos de la Geografía y de las implicaciones diversas que envuelven esta disciplina escolar.

Palabras clave: representaciones sociales; tesis y disertaciones; enseñanza de la Geografía.

\section{INTRODUÇÃO}

A Teoria das Representações Sociais (TRS) foi idealizada por Serge Moscovici em 1961. Esse teórico, de origem romena, desenvolveu seus estudos em Paris/ França, compreendendo os vários estratos daquela sociedade, sobre as representações que se faziam da Psicanálise na visão do senso comum. Moscovici acreditava que as representações são dinâmicas e, ao mesmo tempo que são individuais, são de natureza social, porque ocorrem por meio das interações sociais grupais, ou seja, quando formatamos uma ideia, um conceito ou até mesmo uma opinião, recebemos e/ou colaboramos com as concepções que circulam socialmente por meio de simbologias. 
Para explicar o funcionamento das representações sociais (RS), Moscovici (1978; 2015) se valeu, além de outros conceitos, de dois processos: ancoragem e objetivação. O primeiro diz respeito ao que temos armazenado em nossa memória e que nos ajuda a conhecer algo novo, portanto não familiar. Já o segundo diz respeito ao processo de materialização do referido objeto de conhecimento. Ou seja, o que nos era estranho foi ancorado em algo "semelhante" e, com isso, nos permitiu armazenar em nosso repertório, tornando assim conhecido, portanto, fácil de ser explicado, compreendido e aplicado.

Ainda em evolução, a TRS apresenta os seus desdobramentos, que a caracterizam de acordo com as contribuições dos contemporâneos moscovicianos, como Denise Jodelet, tida como a principal divulgadora das ideias de Moscovici. Ao conceituar RS, essa autora assinalou que se trata de "[...] uma forma de saber prático ligando um sujeito a um objeto" (JODELET, 2001, p. 27), portanto, se trata de uma forma interacional de conhecimento. Outro teórico adepto das ideias defendidas por Moscovici foi Jean-Claud Abric, cuja preocupação é explicar como se organizam as estruturas que compõem uma representação, sendo uma central e outra periférica. À primeira denominou de núcleo central das representações, e o caracterizou como as ideias, conceitos, comportamentos e outros que são resistentes a mudanças. Por outro lado, o que é mais maleável às mudanças, designou de sistema periférico (ALVES-MAZZOTTI, 2008). Outro teórico que acrescentou conhecimentos à TRS foi Willem Doise, que enfatiza questões societais na formação e divulgação das RS. Ivana Marková, por sua vez, se preocupa com a dialogia na formação e modificação das RS (ARRUDA, 2015).

O objeto de estudo da Geografia é o espaço, e nele ocorrem as interações entre o homem e o meio, que são estudadas pelos geógrafos. Na geografia tradicional, o ensino pautava-se na descrição dos seus conteúdos físicos, nesse caso, a boa memória era fundamental para decorar nomes de rios, países, capitais, alturas de montanhas etc. Porém, com o surgimento da Geografia crítica, a preocupação com processos sociais incentivou discussões sobre desigualdades sociais, luta de classes, pobreza, injustiças e esgotamento de recursos naturais. A Geografia humanística passou a valorizar o homem nos espaços geográficos, a partir de como ele sente e vivencia o lugar, que é carregado de sensações. Dessa forma, não cabia mais à Geografia tratar apenas de aspectos físicos, era preciso que ela abordasse também aspectos humanos, interligando-os. Assim, o papel 
do professor em relação ao ensino mudou, agora ele se tornaria um mediador entre os alunos e o conhecimento, cuja função primordial seria despertar neles o olhar geográfico, que permite entender o espaço, sua dinâmica e como agir nele (COSTA; ROCHA, 2010).

Com base no estado do conhecimento do uso da TRS para o ensino da Geografia, nosso estudo justifica-se pela necessidade de se compreender como os docentes de Geografia concebem, por meio de suas práticas pedagógicas, a ação de (não) aprendizagem do estudante, e como esses concebem o contexto e as práticas sociais e pedagógicas para o estudo dessa área de conhecimento.

\section{PROCEDIMENTOS METODOLÓGICOS}

Para a realização deste trabalho, selecionamos pesquisas stricto sensu cadastradas no banco de teses e dissertações na Coordenação de Aperfeiçoamento de Pessoal e Nível Superior (CAPES), defendidas no período de 2012 a 2016. Num primeiro momento, selecionamos sete teses e trinta dissertações, no entanto, a partir de uma leitura mais criteriosa, descartamos duas teses e cinco dissertações, por não atenderem aos critérios de nossa pesquisa. Assim sendo, analisamos 29 trabalhos, sendo quatro teses e 25 dissertações.

Os descritores de busca, para a localização dos títulos e análise dos resumos, foram: "representações sociais", "representação social" (no singular) e "Geografia".

A análise que se segue encontra-se organizada em dois quadros, um gráfico e cinco categorias de análise, segundo proposta de Bardin (2016), sendo que nossa organização semântica somou cinco categorias, a saber: Representações sociais de escola e de ensino da Geografia em regiões fronteiriças (2); Representações sociais de diversidade social e educação inclusiva compreendendo termos da Geografia (6); Representações sociais de professores e graduandos sobre Geografia e práticas pedagógicas (7); Representações sociais de estudantes da Educação Básica sobre conceitos/conteúdo da Geografia (8); Representações sociais de alunos da Educação Básica e de seus professores e outros sobre temas da Geografia (6).

\section{ANÁLISE DAS TESES E DISSERTAÇÕES (2012-2016)}

Na primeira parte de nossa análise, apresentamos a distribuição das 25 dissertações e das quatro teses selecionadas para nossa análise por ano de defesa, 
em seguida, realizamos a classificação das referidas pesquisas por produção nas universidades localizadas nas cinco regiões brasileiras, bem como se são oriundas de instituições públicas ou privadas. Em seguida, demonstramos a incidência do uso dos principais teóricos da TRS utilizados nas pesquisas analisadas. Por fim, de acordo com o que anunciamos anteriormente, organizamos as pesquisas por meio de cinco categorias de análise, de acordo com Bardin (2016).

O quadro a seguir apresenta a distribuição por ano de defesa (2012-2016) das teses e dissertações na área de Geografia que se utilizaram da TRS para sustentação teórica.

Quadro 1- Pesquisas sobre a TRS e o ensino de Geografia, distribuídas no período 2012-2016

\begin{tabular}{|c|c|c|c|}
\hline $\begin{array}{c}\text { Anos } \\
\text { (2012-2016) }\end{array}$ & Teses & Dissertações & Total \\
\hline 2012 & - & 6 & 6 \\
\hline 2013 & - & 2 & 2 \\
\hline 2014 & 3 & 7 & 10 \\
\hline 2015 & - & 6 & 6 \\
\hline 2016 & 1 & 4 & 5 \\
\hline TOTAL & $\mathbf{4}$ & $\mathbf{2 5}$ & $\mathbf{2 9}$ \\
\hline
\end{tabular}

Fonte: As autoras, a partir das teses e dissertações pesquisadas na CAPES (2018).

Conforme o quadro acima, analisamos quatro teses, sendo três defendidas no ano de 2014 e uma em 2016. Não localizamos teses que se fundamentaram na TRS nos anos de 2012, 2013 e 2015. Quanto às dissertações, analisamos seis que foram defendidas em 2012, duas em 2013, sete em 2014, seis em 2015 e quatro em 2016.

O quadro a seguir apresenta a distribuição das dissertações e teses por regiões brasileiras e por esferas administrativas. 
Quadro 2- Distribuição da pesquisa por regiões brasileiras, por esfera administrativa/instituição e programa de pós-graduação

\begin{tabular}{|c|c|c|c|c|c|c|c|}
\hline \multirow{2}{*}{$\begin{array}{c}\text { Regiões } \\
\text { brasileiras }\end{array}$} & \multicolumn{2}{|c|}{$\begin{array}{c}\text { Teses (T) } \\
\text { Dissertações (D) }\end{array}$} & \multirow{2}{*}{$\begin{array}{l}\text { TOTAL } \\
\text { T/D }\end{array}$} & \multicolumn{3}{|c|}{ Esferas Administrativas } & \multirow{2}{*}{ TOTAL } \\
\hline & $\mathbf{T}$ & D & & $\begin{array}{l}\text { Públicas } \\
\text { Federais }\end{array}$ & $\begin{array}{l}\text { Públicas } \\
\text { Estaduais }\end{array}$ & Privadas & \\
\hline Norte & - & 1 & 1 & 1 & - & - & 1 \\
\hline Nordeste & 2 & 9 & 11 & 11 & - & - & 11 \\
\hline Centro-Oeste & - & 4 & 4 & 3 & 1 & - & 4 \\
\hline Sudeste & - & 3 & 3 & 1 & 1 & 1 & 3 \\
\hline Sul & 2 & 8 & 10 & 9 & 1 & - & 10 \\
\hline TOTAL & 4 & 25 & 29 & 25 & 3 & 1 & 29 \\
\hline
\end{tabular}

Fonte: As autoras, a partir das teses e dissertações pesquisadas na CAPES (2018).

Conforme os dados acima, das 29 pesquisas que se valeram dos pressupostos da TRS como referencial teórico-metodológico, um considerável número foi produzido na região nordeste $(37,9 \%)$, seguidas pela produção da região sul $(34,5 \%)$, enquanto a região Centro-Oeste ficou com $13,8 \%$, já a região sudeste obteve $10,3 \%$ das referidas pesquisas, e a norte ficou com a menor quantidade, $3,5 \%$ dos trabalhos.

A maioria das teses e dissertações analisadas são provenientes de instituições públicas federais $(86,2 \%)$, já as universidades públicas estaduais respondem por $(10,3 \%)$ das pesquisas e, localizamos apenas uma pesquisa oriunda da esfera privada $(3,5 \%)$.

No que se refere ao programa em que as pesquisas foram desenvolvidas, 22 delas $(75,9 \%)$ foram realizadas em Programas de Pós-Graduação em Geografia, 6 (20,7\%) foram feitas em Programas de Pós-Graduação em Educação, e 1 $(3,5 \%)$ foi realizada em Programa de Pós-Graduação em Territórios e Expressões. Constatamos também que a maioria das teses e dissertações oriundas dos Programas de Pós-Graduação em Geografia são procedentes das universidades federais, já os estudos realizados nas universidades estaduais provêm dos Programas de Pós-Graduação em Educação.

O gráfico a seguir apresenta a incidência em que os principais teóricos da TRS foram referenciados no total de teses e dissertações por nós pesquisadas. 
Gráfico 1- Apresenta em quantos trabalhos analisados os estudiosos da TRS foram utilizados

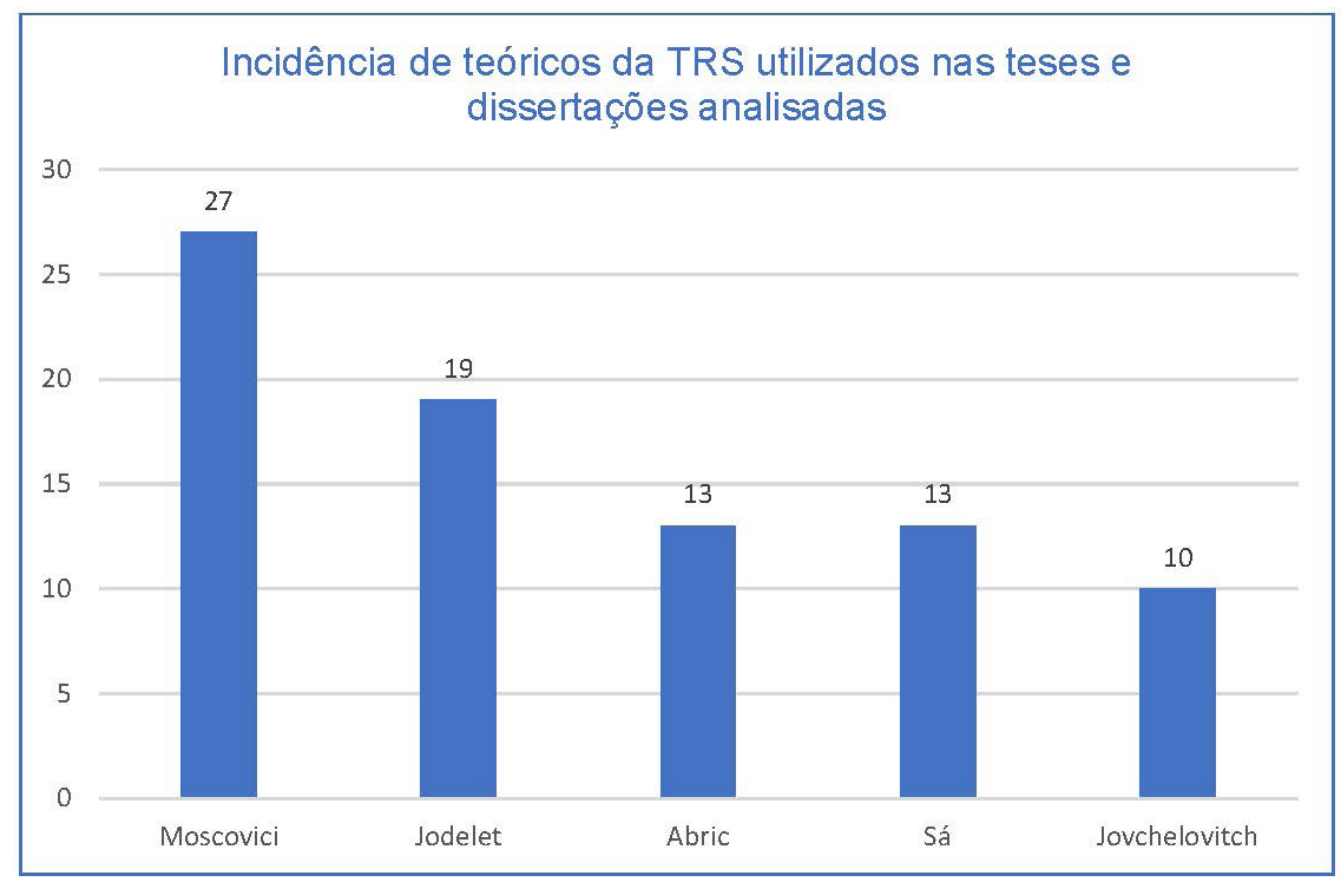

Fonte: As autoras, a partir das teses e dissertações pesquisadas na CAPES (2018).

'O gráfico acima mostra que Serge Moscovici, o idealizador da TRS, foi utilizado por $22(75,9 \%)$ dos pós-graduandos que realizaram pesquisas em RS; a segunda autora mais utilizada foi Denise Jodelet, citada por $19(65,5 \%)$ pesquisadores, por sua vez Jean-Claude Abric e Celso Pereira de Sá, respectivamente, constaram cada qual em 13 (44,8\%) das pesquisas e Sandra Jovchelovitch apareceu em 10 (34,5\%) das pesquisas stricto sensu. Em menor número de incidência, outros autores foram referenciados, como Pedrinho Guareschi, Angela Arruda, Judith Alves-Mazzotti, Marcia Rangel, Willen Doise, Claude Flament, Mary Jane Spink, Ivana Marková, Gerard Duveen dentre outros.

Na sequência, apresentamos uma síntese dos vinte e nove trabalhos analisados, os quais foram organizados em cinco categorias semânticas. 


\section{APRESENTAÇÃO DAS CATEGORIAS DE ANÁLISE}

\subsection{Representações sociais de escola e de ensino da Geografia em regiões fronteiriças}

Dois estudos compõem a presente categoria de análise. Bertin (2014) analisou as RS e espaciais da Tríplice Fronteira (Brasil, Argentina e Paraguai), caracterizada pela presença do fenômeno turístico e de interações entre as populações dos três países. A pesquisadora buscou compreender como o ensino da Geografia contribui para uma aprendizagem significativa, marcada pela diversidade cultural e multiculturalismo dos educandos. Para isso, a coleta de dados foi realizada em escolas públicas e privadas localizadas no Brasil, na Argentina e no Paraguai. Participaram da pesquisa 416 alunos do ensino médio, que responderam a questionário e elaboraram mapas mentais. Constatou-se, por meio das RS dos participantes da pesquisa, que as práticas sociais vivenciadas pelos pesquisados se encontram distanciadas dos conteúdos estruturantes de Geografia ensinados pela escola.

Santos (2016) buscou compreender as dinâmicas construídas por uma escola brasileira situada na fronteira das cidades-gêmeas de Guajará-Mirim (RO/ $\mathrm{BR}$ ) e Guayaramerin (BENI/BOL). Trata-se de uma pesquisa participante, na qual a pesquisadora foi a moderadora no Grupo de Discussão sobre o que a escola campo da pesquisa vem realizando nos últimos cinco anos sobre as suas práticas transfronteiriças. Participaram do estudo cinco alunos brasileiros e cinco bolivianos; quatro professoras e quatro pais. Foram aplicados mapas mentais sobre o que cada participante pensa da escola. Os resultados revelam o trabalho singular realizado pela escola brasileira no acolhimento e no atendimento aos seus estudantes e seus familiares bolivianos.

\subsection{Representações sociais de diversidade social e educação inclusiva compreendendo termos da Geografia}

Seis estudos compõem esta categoria de análise. Jesus (2012) analisou as RS dos docentes do Curso de Licenciatura em Geografia da Universidade Estadual do Maranhão sobre os desafios da inclusão de alunos com deficiência visual no ensino superior. Participaram da pesquisa 10 professores do referido 
curso de graduação e um aluno com deficiência visual, os quais responderam a questionário de perfil socioeconômico e a entrevista semiestruturada, além de entrevista em profundidade respondida pelo aluno participante, que foram analisadas a partir da técnica da análise de conteúdo de Bardin. Os resultados indicam pontos positivos em relação às inter-relações entre os entrevistados, e estes representam a necessidade de se adotar medidas para contornar os obstáculos postos pelas limitações docentes e discentes presentes nos processos de inclusão.

Machado (2012) em sua pesquisa verificou se seria possível lugarização do sujeito a partir de sua metalinguagem, facilitando, ou não, a construção do conhecimento geográfico na correlação entre Geografia e o movimento hip hop. Para isso, o autor se valeu de pesquisa participante, sendo que inicialmente se deu pelo trabalho com conceitos geográficos: espaço, lugar, território e paisagem, cultura, identidade, cidade, RS, espaço-escola e comunicação. Foram realizadas quinze entrevistas semiestruturadas com representantes do hip hop do estado do Rio Grande do Sul e cinco com professores da rede pública municipal de Porto Alegre, RS. As conclusões preliminares de Machado (2012) apontam que o referido movimento pode corroborar com a lugarização do sujeito, na busca do equilíbrio na construção geográfica mais humana.

Menezes (2014), no intento de pesquisar sobre a representação do lugar por meio de um estudo sobre juventude ribeirinha da comunidade de Nazaré-RO, buscou identificar as relações entre as representações masculinas e femininas no contexto das relações de gênero. A seguir, analisou a dinâmica espacial que estabelecem mudanças e/ou permanências para fase juvenil. Por fim, teceu reflexões sobre as relações dos jovens ribeirinhos com "mundo moderno" mesmo estando em um contexto rural. A partir de metodologia qualitativa aliada à observação participante, Menezes (2014) utilizou mapas mentais, entrevistas e questionário aberto para obter informações sobre os jovens com idade entre 15 a 29 anos, e uma entrevista com um integrante do grupo musical e cultural "Minhas Raízes". Os resultados obtidos permitiram perceber que há várias formas de externar o sentido e a representação do "lugar", tanto nos mapas, como nos relatos dos jovens. As RS dos participantes revelam aspectos de mudanças nas práticas sociais dos jovens, suas relações cada vez mais próximas com os elementos urbanos, a saída dos jovens para morar na cidade, e os problemas com álcool e drogas vividos dentro 
da comunidade. Contudo, foram observados o sentimento de pertencimento e o apreço de todos pela Comunidade de Nazaré.

Weissböck (2014) buscou compreender as RS e as disposições que os jovens votantes de 16 e 17 anos, matriculados em escola pública que oferta cursos na modalidade regular e técnica na cidade de Guarapuava, PR, têm sobre o sistema político e ao reconhecimento de respectivas formas de legitimidade política (voto), bem como se essas representações proporcionam a formação de uma identidade política. Trata-se de uma pesquisa empírica, em que foram aplicados 97 questionários na Escola Carneiro Martins, no período pré-eleição municipal em 2012. A pesquisadora constatou que os jovens se consideram parte de um grupo preocupado com a política do país, mas são descrentes em relação às instituições políticas, e que há uma negação frente às formas tradicionais de participação, sendo que as ações coletivas juvenis parecem ser de caráter descontínuo e conformista. Além disso, esses jovens compreendem a política como sendo algo restrito à política partidária, e não às relações cotidianas. Por outro lado, mostram-se motivados a participar de determinadas ações em prol de algo que acreditam e, portanto, sentem a necessidade de uma formação política e político-partidária.

Oliveira (2015) pesquisou sobre as representações de indígenas na sala de aula e nos livros didáticos, para isso buscou diagnosticar e sugerir possibilidades para instigar o interesse e a discussão sobre a história e a cultura indígena na sala de aula a partir de textualidades indígenas, em turmas do Ensino Fundamental II de algumas escolas públicas do Estado de Goiás. Buscou-se analisar também as representações formuladas por alunos sobre os indígenas, tomando como ponto de partida uma análise comparativa entre estudantes de escolas de Itapuranga, Morro Agudo de Goiás e Waldelândia, que estão localizadas em uma região conhecida como Vale São Patrício, onde vive uma das três etnias indígenas sobreviventes do estado de Goiás, os Tapuias do Carretão. Os resultados mostram que as coleções de livros didáticos de História, Geografia e Língua Portuguesa analisados nessa pesquisa não apresentam conteúdos sobre os povos indígenas do Estado do Goiás.

Silva (2015) objetivou em sua pesquisa compreender as RS da juventude estudantil a respeito da escola e de seu vínculo com o trabalho formal, em específico, o caso do ensino médio na Região Administrativa do Gama, DF. A pesquisa 
foi desenvolvida em três instituições públicas: Centro de Ensino Médio 1, Centro de Ensino Médio 2 e Centro de Ensino Médio 3. Os sujeitos da pesquisa foram compostos por estudantes do 30 ano do ensino médio. Elegeu-se, para efetivação da pesquisa, o uso das metodologias quantitativa e qualitativa. Os instrumentos de pesquisa consistiram na aplicação de questionários e na realização de entrevistas semiestruturadas. Foi verificado que, embora a escola seja caminho que conduz ao trabalho e ao ensino superior, o trabalho comparece com bem mais intensidade. Este está nos planos imediatos de praticamente todos os estudantes pesquisados. A universidade também é pretendida, porém, pode esperar para os anos vindouros. A segunda situação, que se evidencia, é a centralidade que o trabalho ocupa na vida dos jovens. Estes acabam por vê-lo como uma forma de ganhar a independência e a autonomia.

\subsection{Representações sociais de professores e graduandos sobre Geografia e práticas pedagógicas}

Sete estudos compõem esta categoria de análise. Sander (2012), em sua pesquisa, objetivou compreender as RS de professores sobre meio ambiente e a relação dessas representações com as práticas pedagógicas em educação ambiental. Participaram do estudo 51 professoras dos quartos e quintos anos do Ensino Fundamental, de uma rede municipal de ensino. A partir da análise de dados, concluiu-se que as RS de meio ambiente da maioria dos professores participantes é a de "conscientizar para preservar a natureza", uma compreensão de foco naturalista e que possui aspectos antropocêntricos. As análises das entrevistas e da apreciação de registros docentes apresentaram resultados complementares, sendo que a maioria representa as práticas pedagógicas em educação ambiental fortemente voltadas a práticas conservadoras.

Soller (2012) pesquisou o lugar do turismo na leitura da paisagem geográfica e sua relação com o ensino da Geografia, procurando compreender, ainda que de forma provisória, a construção do espaço turístico. A referida pesquisa compreendeu análise documental e entrevista episódica com 25 sujeitos, dentre eles professores de Geografia da rede pública de Garopaba, SC, turistas, veranistas, atores do Turismo, moradores e sujeitos que não conheciam o espaço estudado. Para isso, a autora se valeu de observação de campo, codificação e triangulação de dados. Os resultados apontam que o ensino crítico da Geografia é importante 
para a construção da leitura da paisagem geográfica.

Pimentel Neto (2013), em sua pesquisa, evidenciou o conteúdo e a estrutura da RS de Geografia articulada por 51 professores participantes da pesquisa que atuam nos anos iniciais do Ensino Fundamental, em seis escolas públicas municipais de Teresina, PI. Os resultados revelaram que a maioria dos(as) professores(as) enfrentam grandes dificuldades para lecionar a disciplina Geografia, pela limitação que possuem em relação ao domínio de metodologias e conteúdo específicos de Geografia, por conta disso têm pautado suas práticas no uso quase que exclusivo do livro didático, por meio de método expositivo e com a realização de atividades de caráter estritamente mnemônico.

Albino (2014), em seu estudo, analisou as RS que os licenciandos do Instituto Federal de Educação, Ciência e Tecnologia do Rio Grande do Norte (IFRN) têm de disciplinas didático-pedagógicas. Participaram da pesquisa 120 graduandos dos cursos de Biologia, Espanhol, Física, Geografia, Informática, Matemática e Química do IFRN, sendo que 30 estudantes responderam à Técnica de Associação Livre de Palavras (TALP), e 90 deles responderam ao Procedimento de Classificações Mínimas (PCM). Além da interpretação dessa metodologia, Albino (2014) se valeu de Análise de Conteúdo de Bardin e Multidimensional. Os resultados apontam que os pesquisados ancoram suas RS nas disciplinas didático-pedagógicas pelas quais, metodologicamente, seus professores Ihes ensinam a ser professores, e objetivam a imagem do bom professor alcançada por meio do processo formativo e das experiências nele vivenciadas.

Pimentel (2014) analisou as RS da formação continuada partilhada por professores de Geografia. Como instrumentos de pesquisa, foram utilizados um questionário e uma entrevista estruturada com 10 professores de Geografia de escolas municipais de Teresina, PI. Constatou-se que a representação do grupo social investigado é marcada por pensamentos generalizantes sobre a formação continuada, evidenciando a dificuldade dos sujeitos em dominarem o conhecimento teórico para realizarem intervenções na prática da sala de aula. A representação social da formação continuada partilhada pelos interlocutores dessa pesquisa se aproxima do conhecimento científico, embora com fortes traços do senso comum e aponta para uma valorização e qualificação das suas práticas pedagógicas. Os principais obstáculos representados pelos participantes que dificultam sua formação, foram a falta de incentivos, principalmente financeiro, e a ausência 
da prática, aspectos que influenciam na forma de pensar e agir desses sujeitos, inviabilizando suas participações nas aulas da referida formação.

Gomes (2014) investigou as RS de três professores, sendo dois de História e um de Geografia, acerca da Lei 10.639/03 como processo desencadeador de redes simbólicas cujos valores norteiam as práticas pedagógicas do grupo de docentes estudado. Para a coleta de dados, utilizou-se de procedimentos tais como: entrevista semiestruturada, diário de bordo e observação participante. Apurou-se que, para os participantes da pesquisa, o contato com o debate racial se deu, sobretudo, na atuação profissional. A pesquisadora sugere que os cursos de formação inicial e continuada devem considerar essa dimensão da formação docente.

Carvalho (2016) buscou conhecer as RS dos professores de Geografia, da rede pública estadual na cidade de Santos, SP, a respeito de sua formação inicial. A pesquisa se desenvolveu em três etapas: primeiro, foram realizadas entrevistas exploratórias com três professores; em seguida, foi aplicado um questionário com questões abertas e fechadas a 25 professores; e, na terceira etapa, foram efetuadas entrevistas de aprofundamento com dois professores recém-formados e dois estudantes de Geografia. Os resultados se ancoram em duas dimensões de análise: a dimensão formativa relativa aos saberes necessários à docência e a dimensão profissional, relativa aos desafios do início de carreira. Em suas respostas, os professores enfatizaram alguns obstáculos como a formação inadequada, as dificuldades inter-relacionais e o enfrentamento da realidade escolar.

\subsection{Representações sociais de estudantes da Educação Básica sobre conceitos/conteúdo da Geografia}

Oito estudos compõem esta categoria de análise. Oliveira (2012) buscou compreender como está sendo formado o conceito do Cerrado e analisou a influência que o ensino exerce sobre os discentes que serão agentes do espaço em um futuro próximo. Participaram da pesquisa 379 alunos do último período do ensino médio, de cinco escolas públicas, os quais responderam à TALP. Para o tratamento dos dados, foi utilizado o software EVOC. Os resultados apontam que os pesquisados elaboraram RS apenas dos aspectos naturais em relação ao Cerrado, já os socioambientais não foram representados, fato que precisa ser refletido no processo de ensino desses estudantes.

Pereira (2012), no intuito de identificar as RS do continente africano pre- 
sentes em alunos do ensino fundamental e médio, realizou pesquisa qualitativa em duas turmas de alunos (oitavo ano do Ensino Fundamental e 1음 ano do ensino médio), com a utilização de duas técnicas: grupo focal e análise do jornal Zero Hora (93 edições, de 2009 a 2011, que se reportassem a algum aspecto do continente africano). Os resultados apontaram que as RS do continente africano pelos alunos participantes da pesquisa são muito próximas das representações da mídia, quase sempre com atribuições negativas.

Ferreira (2014), em sua pesquisa, buscou reconhecer as experiências que caracterizam Canoas-RS como lugar para os jovens que convivem na cidade. Participaram da pesquisa alunos do 9 o ano de duas escolas do Município de Canoas, RS. A metodologia utilizada foi a construção de fanzines em sala de aula e entrevistas individuais com posterior análise de conteúdo. Os resultados apontam para a necessidade de considerar diversas representações dos jovens sobre a cidade como lugar conforme a localização de moradia e possibilidades de apropriação da cidade na contemporaneidade.

Silva (2014), em sua dissertação, buscou conhecer as representações socioespaciais da cidade de Cuiabá, MT, segundo 40 crianças de quatro escolas da rede municipal de ensino da mesma cidade, para compreender as significações das crianças acerca da cidade, bem como identificar diferentes trajetos por elas percorridos. O procedimento metodológico adotado foi a recolha de desenhos da cidade, baseados na proposta dos mapas cognitivos, acompanhados de entrevista semiestruturada, com quatro grupos de 10 crianças, cada subgrupo pertencente a uma das quatro escolas municipais selecionadas. Foram utilizados os softwares CHIC e ALCESTE para análise do material. Por fim, realizou-se análise compreensiva da entrevista e respectivo mapa cognitivo de dois sujeitos. Os resultados evidenciam indícios da existência de uma tensão entre a tradição e a modernidade permeando as representações socioespaciais das crianças a respeito da cidade. Nota-se que as crianças avaliam a cidade e orientam seus deslocamentos pelo critério da estética, da violência e das suas relações afetivas com outros atores sociais, revelando que o afeto e a significação em relação aos lugares estão intimamente ligados ao afeto entre as pessoas que neles convivem.

Santos (2015) buscou entender como os jovens compreendem os espaços que Ihes são ausentes, por meio da leitura de maquetes. Participaram da pesquisa 29 alunos, sendo 22 de uma escola particular de Porto Alegre, RS e 7 de 
uma escola estadual de Faxinal do Soturno, RS. A faixa etária dos alunos foi de 12 a 15 anos. Os alunos foram divididos em grupos, em suas respectivas escolas, para confeccionarem as maquetes (sete ao total). Para a confecção das maquetes foram utilizadas oito etapas: contextualização, projeto, construção, croqui, legenda, relatório, conclusão e exposição. Os resultados apontam que os alunos representam os espaços simbólicos a partir das vivências de seu cotidiano, ao ponto que, quando refletem sobre algo que não Ihe é cotidiano, eles partem para essa reflexão utilizando suas experiências.

Gonçalves (2015) buscou interpretar o Cerrado goiano a partir das RS dos alunos do Ensino Fundamental II, das escolas rurais do município de Rio Verde, GO. Foram aplicados questionários em 80 alunos, com questões semiestruturadas. Foi solicitada, ainda, a produção de desenho espontâneo, permitindo aos alunos ilustrarem as representações do Cerrado. A interpretação de desenhos dos educandos demonstra que há um grupo que considera o Cerrado modernizado e urbanizado, e que apresenta em sua concepção as ações que transformam o território do Cerrado. No entanto há um grupo que representa o Cerrado natureza, em que se destaca uma paisagem lírica e perfeita da natureza. Por fim, há um outro grupo de educandos que enfatiza o Cerrado problemas ambientais, desenhando diversos problemas, como desmatamento e poluição, que, consequentemente, acarretam prejuízos e transformam o território do Cerrado.

Leão (2015) analisou a RS do processo migratório partilhada pelos alunos do Ensino Médio da Rede Estadual de Ensino em Campo Maior-PI. A pesquisa foi realizada nesse município por este apresentar um fluxo de migração significativo em relação a outros municípios piauienses. Como suporte teórico, a pesquisa foi embasada na TRS, com ênfase na Teoria complementar do Núcleo Central, desenvolvida por Jean-Claude Abric. Foram utilizados os seguintes procedimentos de coleta de dados: pesquisa bibliográfica, pesquisa documental, questionários, entrevistas e o Teste de Associação Livre de Palavras (TALP). Evidenciou-se que a RS de processo migratório compartilhada pelos pesquisados é consolidada como um aspecto positivo. Os alunos atribuem a esse processo as soluções para questões de infraestrutura relacionadas ao município de Campo Maior, PI. Para Leão (2015), essa RS é pautada nas experiências vivenciadas por eles, concretizadas nas características econômicas do município e aspectos sociais e culturais da população. 
Silva (2016), em sua dissertação, analisou as RS do espaço geográfico piauiense em um grupo de 117 alunos do 3ํano do Ensino Médio da rede pública de ensino em Teresina, PI. As escolas participantes da pesquisa foram escolhidas segundo o bom desempenho no Exame Nacional do Ensino Médio (ENEM). Para a coleta de dados foram utilizados o Teste de Associação livre de Palavras (TALP) e um questionário. Na tabulação, tratamento e análise dos dados foi feito uso dos softwares Word, Excel e EVOC. As evocações obtidas evidenciaram a presença marcante das características naturais desse espaço, ora como limitadoras da ação humana, ora como potencialidades. Silva (2016) percebeu que, em relação aos aspectos físicos, mais visíveis aos alunos, aqueles predominaram na construção do significado que estes atribuem ao espaço piauiense. A RS de espaço geográfico do Piauí capturada apresenta um misto de aspectos do senso comum com poucas características do conhecimento científico, com a representação de um espaço com extenso território, com um meio ambiente comprometido, dotado de uma importante rede hidrográfica, com destaque para os rios Parnaíba e Poti, com cidades que se caracterizam pela carência de recursos financeiros e a má administração dos gestores da coisa pública.

\subsection{Representações sociais de alunos da Educação Básica e de seus professores e outros sobre temas da Geografia}

Seis estudos compõem esta categoria de análise. Malanski (2013) estabeleceu uma síntese analítica geográfica de um espaço escolar público a partir de representações de pessoas que o vivem diariamente. Fez-se uso do recurso de mapeamento mental coletivo, uma forma de representação que valoriza a interação social e facilita a leitura e interpretação do material cartográfico. Participou da pesquisa um grupo de 10 sujeitos, sendo um professor, um funcionário e oito alunos da EJA de uma escola pública. A leitura e análise do mapa mental coletivo e a síntese qualitativa revelam que o espaço escolar analisado é reificado e compartimentado em vários outros espaços menores, predominantemente funcionais e hierarquizados. Além disso, pode-se assumir que esses espaços possuem baixa imaginabilidade, e muitos apresentam aspectos topofóbicos e de não lugar.

Costa (2014) investigou as RS da prova como instrumento avaliativo no ensino de Geografia, da rede pública do município de Terezina, PI. Os sujeitos da 
pesquisa foram estudantes e 40 professores de Geografia da Educação Básica. Para os estudantes do 3 o ano do Ensino Médio e $9^{\circ}$ ano do Ensino Fundamental, foi aplicado o Teste de Associação Livre de Palavras (TALP) e analisado por meio do EVOC. Os professores responderam a um questionário de pesquisa com a finalidade de adquirir informações acerca da sua prática avaliativa na disciplina de Geografia em escolas públicas municipais e estaduais de Teresina-PI. Em relação às RS evocadas, o consenso fica em torno de uma concepção de Geografia como ciência de conteúdo amplo, diverso e pouco contextualizado, sendo, portanto, de difícil apreensão do ponto de vista dos instrumentos avaliativos.

Silva (2014), em sua tese, analisou as formas pelas quais a temática patrimonial ambiental urbana é promovida na educação escolar, a fim de avaliar em que medida as ações e projetos educativos incorporam as representações, valores e práticas cotidianas que os grupos sociais escolares e circunvizinhos expressam em relação aos patrimônios ambientais representados pelos bens lacustres em Fortaleza, CE. Foram analisadas as RS de alunos, professores, coordenação pedagógica e moradores pescadores ou transeuntes, sobre quatro lagoas, por meio de entrevista. Como resultado, o estudo evidencia a ausência de um projeto educacional que concilie as questões ambientais e patrimoniais numa abordagem pautada pelos valores socioculturais, expressos nas representações dos grupos sociais escolares e residentes no entorno dos sítios lacustres.

Pinheiro (2015) analisou a RS de paisagem entre os alunos da 1a série do ensino médio das escolas públicas estaduais de Teresina, $\mathrm{PI}$, bem como a influência do trabalho docente para a permanência ou transformação dessas representações. Os meios de investigação compreenderam pesquisa bibliográfica e de campo. A pesquisa bibliográfica esteve ancorada em autores da TRS e da Geografia. A pesquisa foi realizada em quatro escolas estaduais do município de Teresina, PI, uma para cada zona administrativa da cidade que ofertam o Ensino Médio. Como instrumentos de coleta de dados, foram utilizados um questionário socioeconômico e um Teste de Associação Livre de Palavras (TALP) dos alunos e uma entrevista estruturada nos professores. Os resultados revelaram indícios significativos da existência de uma representação social, corroborando com a hipótese central desta pesquisa, na qual se supõe que os elementos da ideia de paisagem identificados na representação social dos alunos estejam relacionados ao senso comum, com pouca influência do conhecimento geográfico sobre paisagem ao 
qual tiveram contato durante a educação básica.

Silva (2016) analisou as RS de cidade pelos alunos do 9o ano do Ensino Fundamental das escolas públicas municipais da zona rural de Teresina, Pl, e sua pesquisa também intencionou contribuir para uma melhor prática docente no cotidiano da sala de aula sob a mediação do ensino de Geografia. As turmas dos 9o anos que representaram a amostra para o desenvolvimento dessa análise pertencem a cinco Escolas Municipais de Teresina. Foram utilizados os seguintes instrumentos: questionário, Teste de Associação Livre de Palavras (TALP), que foi aplicado junto aos alunos, e uma entrevista semiestruturada aplicada junto aos professores. O software EVOC foi utilizado para realizar o tratamento dos resultados. Os resultados revelaram uma RS que veio corroborar com a hipótese central da pesquisa, na qual se imaginava que a RS de cidade reproduzida no discurso dos alunos do Ensino Fundamental pesquisados, estivesse relacionada ao senso comum, ancorada em concepções fragmentadas e conteudistas, inibindo por vezes a capacidade de participação criativa acerca da produção do conhecimento pelos sujeitos sociais, reflexo, de certa forma, na forma como eles são mediados na aprendizagem dos conhecimentos de Geografia.

Por fim, Martins (2016) analisou a concepção de natureza construída pelos estudantes do Ensino Fundamental a partir dos conteúdos escolares de Geografia. A metodologia utilizada na pesquisa parte da abordagem da pesquisa qualitativa e contemplou: revisão bibliográfica sobre a conceituação de natureza na Geografia; levantamento das RS sobre a natureza de estudantes do sexto ano do Ensino Fundamental com base na teoria desenvolvida por Moscovici (1978); aplicação de questionários com os professores para a caracterização do grupo participante e informações complementares; análise de conteúdo dos dados levantados. Os resultados obtidos demonstram que a concepção de natureza dos estudantes e professores nas aulas de Geografia é plural e multifacetada, pois não se trata de uma visão influenciada por determinada corrente filosófica do pensamento geográfico, mas sim de ideias que expressam ora uma natureza idílica e contemplativa, ora uma natureza de uso-recurso.

\section{CONSIDERAÇÕES FINAIS}

A presente pesquisa teve como objetivo analisar o uso da TRS como referencial teórico-metodológico para o ensino da Geografia na educação básica. 
Com base na seleção e análise das pesquisas que compõem esse presente estudo, consideramos importante a escolha da TRS pelos autores das teses e dissertações por nós analisadas, ao utilizá-la para referenciar suas investigações e compreender as RS sobre aspectos da Geografia, seja pelo olhar de estudantes, professores e outros atores sociais que foram ouvidos pelos vinte e nove pesquisadores.

Em nossa apreciação sobre o material estudado, percebemos a grande relevância de se compreender as RS de professores e alunos para refletirmos sobre o processo ensino e aprendizagem e para repensar políticas públicas para a Educação.

Realizar este estudo foi importante pelo fato de contribuir para a compreensão dos diferentes referenciais teóricos metodológicos que fundamentam as pesquisas científicas e, em especial, a TRS, que se mostra eficiente para contribuir com o entendimento dos fenômenos educacionais e sociais.

Todavia são necessários mais estudos envolvendo outras temáticas da Educação, que possibilitem conhecer e intervir em situações nas quais os alunos não se apropriam de conteúdos importantes para a compreensão da realidade na qual estão inseridos.

\section{REFERÊNCIAS}

ALBINO, G. G. A representação social de disciplinas didático-pedagógicas no contexto da formação inicial docente: um entremear de saberes. 2014. 240 f. Tese (Doutorado em Educação) - Universidade Federal do Rio Grande do Norte (UFRN), Natal, 2014.

ALVEZ-MAZZOTTI, A. J. Representações sociais: aspectos teóricos e aplicações à educação. Revista Múltiplas Leituras, São Paulo, v. 1, n. 1, p. 18-43, jan./jun. 2008.

ARRUDA, A. Modernidade \& Cia: repertórios da mudança. In: JESUÍNO, Jorge Correia; MENDES, Felismina R. P.; LOPES, Manuel José (Org.). As representações sociais nas sociedades em mudança. Petrópolis, RJ: Vozes, 2015. p. 103-27.

BARDIN, L. Análise do conteúdo. São Paulo: Edições 70, 2016.

BERTIN, M. O ensino da geografia na tríplice fronteira (Puerto Iguazú/AR, Foz do Iguaçu) BR e Ciudad del Leste/PY), e o turismo como possibilidade de reflexão das representações sociais e espaciais. 2014. 209 f. Tese (Doutorado em Geografia)- Universidade Federal do Rio Grande do Sul (UFRGS), Porto Alegre, 2014. 
CARVALHO, M. G. N. Representações sociais dos professores de Geografia a respeito de sua formação inicial. 2016. 218 f. Dissertação (Mestrado em Educação)- Universidade Católica de Santos (Unisantos), Santos, SP, 2016.

COSTA, A. R. A avaliação no ensino de Geografia: representação social da prova como instrumento avaliativo por alunos da educação básica. 2014. 147 f. Dissertação (Mestrado em Geografia)- Universidade Federal do Piauí (UFPI), Teresina, 2014.

COSTA, F. R. da; ROCHA, M. M. Geografia: Conceitos e paradigmas - apontamentos preliminares. Revista Geomae, Campo Mourão, v. 1 n. 2, p. 25-56, jun./dez., 2010.

FERREIRA, D. S. Canoas como lugar: o mundo dos jovens contemporâneos a partir das suas representações sociais. 2014. 150 f. Dissertação (Mestrado em Geografia)- Universidade Federal do Rio Grande do Sul (UFRGS), Porto Alegre, 2014.

GOMES, M. C. R. As representações de um grupo de professores do ensino fundamental acerca da Lei 10.639/03. 2014. 135 f. Dissertação (Mestrado em Educação)- Universidade do Estado de Minas Gerais (UFRN), Belo Horizonte, 2014.

GONÇALVES, F. P. Estudo das representações sociais do cerrado na visão de alunos do ensino fundamental de escolas rurais em Rio Verde - GO. 2015. 146 f. Dissertação (Mestrado em Geografia)- Universidade Federal de Goiás (UFG), Jataí, 2015.

JESUS, I. D. Analisando a educação inclusiva no curso de licenciatura em Geografia na Universidade Estadual do Maranhão. 2012. 98 f. Dissertação (Mestrado em Educação)Universidade Federal do Maranhão (UFMA), São Luís, 2012.

JODELET, D. Representações sociais: um domínio em expansão. In: JODELET, Denise. (Org.). As representações sociais. Rio de Janeiro: EdUERJ, 2001. p. 17-44.

JOVCHELOVITCH, S. Os contextos do saber: representações, comunidade e cultura. 2. ed. Petrópolis, RJ: Vozes, 2011.

LEÃO, P. M. D. A representação social de processo migratório partilhada pelos alunos do ensino médio no município de Campo Maior-Pl. 2015. 124 f. Dissertação (Mestrado em Geografia) - Universidade Federal do Piauí (UFPI), Teresina, 2015.

MACHADO, C. G. R. M. O ensino da geografia e o hip hop. 2012. 176 f. Dissertação (Mestrado em Geografia) - Universidade Federal do Rio Grande do Sul (UFRGS), Porto Alegre, 2012.

MALANSKI, L. M. Representação de espaço escolar a partir de mapeamento coletivo. 2013. 120 f. Dissertação (Mestrado em Geografia) - Universidade Federal do Paraná (UFPR), Curitiba, 2013. 
A Teoria das Representações Sociais como referencial teórico-metodológico na pesquisa em Geografia: análise de teses e dissertações presentes na Capes de 2012 a 2016

MARTINS, C. B. A concepção de natureza na geografia escolar: uma análise das representações sociais de estudantes do ensino fundamental. 2016. 95 f. Dissertação (Mestrado em Geografia) - Universidade do Estado do Rio de Janeiro (UERJ), São Gonçalo, 2016.

MENEZES, E. F. A representação do lugar: um estudo sobre juventude ribeirinha da comunidade de Nazaré-RO. 2014. 136 f. Dissertação (Mestrado em Geografia) Universidade Federal de Rondônia (UFRO), Porto Velho, 2014.

MOSCOVICl, S. Representações sociais: investigações em Psicologia Social. 11. ed. Petrópolis, RJ: Vozes, 2015.

MOSCOVICI, S. A representação social da Psicanálise. Rio de Janeiro: Zahar, 1978.

OLIVEIRA, S. R. L. Formação do conceito do cerrado e do conceito de Geografia: análise dos conhecimentos geográficos de alunos do ensino médio da rede pública estadual de Jataí/Goiás. 2012. 107 f. Dissertação (Mestrado em Geografia) - Universidade Federal de Goiás (UFG), Jataí, 2012.

OLIVEIRA, F. A. S. Entre a realidade e o imaginário: as representações de indígenas na sala de aula e nos livros didáticos. 2015. 179 f. Dissertação (Mestrado em Territórios e Expressões) - Universidade Federal de Goiás (UFG), Anápolis, 2015.

PEREIRA, P. G. O ensino de Geografia e as representações sociais do continente africano para sujeitos alunos. 2012. 158 f. Dissertação (Mestrado em Geografia) - Universidade Federal do Rio Grande do Sul (UFRGS), Porto Alegre, 2012.

PIMENTEL NETO, R. N. A representação social de Geografia pelas professoras e professores dos anos iniciais do ensino fundamental. 2013. 178 f. Dissertação (Mestrado em Geografia) - Universidade Federal do Piauí (UFPI), Teresina, 2013.

PIMENTEL, R. M. S. A representação social da formação continuada partilhada por professores de geografia do ensino fundamental. 2014. 128 f. Dissertação (Mestrado em Geografia) - Universidade Federal do Piauí (UFPI), Teresina, 2014.

PINHEIRO, I. A. Representação social de paisagem por alunos do ensino médio das escolas públicas de Teresina-PI. 2015. 157 f. Dissertação (Mestrado em Geografia)- Universidade Federal do Piauí (UFPI), Teresina, 2015.

SANDER, L. Representações sociais de professores(as) a respeito de meio ambiente $e$ suas práticas pedagógicas escolares em educação ambiental. 2012. 86 f. Dissertação (Mestrado em Desenvolvimento Regional) - Universidade Tecnológica Federal do Paraná (UTFPR), Pato Branco, 2012. 
SANTOS, Z. G. C. Interações e representações sociais: um estudo do espaço escolar em Guarajá-Mirim (RO), na fronteira do Brasil com a Bolívia. 2016. 190 f. Tese (Doutorado em Geografia) - Universidade Federal do Paraná (UFPR), Curitiba, 2016.

SANTOS, L. P. A construção das relações do espaço ausente na geografia escolar. 2015. 197 f. Dissertação (Mestrado em Geografia) - Universidade Federal do Rio Grande do Sul (UFRGS), Porto Alegre, 2015.

SILVA, G. A. F. Representação social de espaço geográfico piauiense partilhada por alunos(as) do 3o ano do ensino médio. 2016. 104 f. Dissertação (Mestrado em Geografia) - Universidade Federal do Piauí UFPI), Teresina, 2016.

SILVA, T. F. S. Representação social de cidade por alunos do ensino fundamental. 2016. 131 f. Dissertação (Mestrado em Geografia) - Universidade Federal do Piauí (UFPI), Teresina, 2016.

SILVA, M. P. Juventude estudantil e as representações sociais da escola e de seu vínculo com o trabalho: o caso do ensino médio na Região Administrativa de Gama-DF. Orientador: Eguimar Felício Chaveiro. 2015. 157 f. Dissertação (Mestrado em Geografia) - Universidade Federal de Goiás (UFG), Goiânia, 2015.

SILVA, E. M. P. Representações socioespaciais da cidade de Cuiabá-MT, segundo crianças. 2014. 250 f. Dissertação (Mestrado em Educação) - Universidade do Estado do Mato Grosso (UFMT), Cuiabá, 2014.

SILVA, N. M. Patrimônio ambiental urbano e representações educacionais do espaço lacustre em Fortaleza (CE - Brasil). 2014. 288 f. Tese (Doutorado em Geografia) Universidade Federal do Ceará (UFC), Fortaleza, 2014.

SOLLER, J. M. O lugar do turismo na leitura da paisagem geográfica e sua relação com o ensino da Geografia. 2012. 254 f. Dissertação (Mestrado em Geografia) - Universidade Federal do Rio Grande do Sul (UFRGS), Porto Alegre, 2012.

WEISSBÖCK, L. P. Representações sociais de jovens votantes de 16 e 17 anos em Guarapuava/PR: territorialidade e comportamento político-partidário. 2014. 248 f. Dissertação (Mestrado em Geografia) - Universidade Estadual do Centro-Oeste (UNICENTRO), Guarapuava, PR, 2014. 


\section{Sobre as autoras:}

Solange Franci Raimundo Yaegashi: Pós-Doutora em Psicologia pela Universidade de São Paulo (USP). Doutora em Educação pela Universidade Estadual de Campinas (UNICAMP). Docente do Departamento de Teoria e Prática da Educação e do Programa de Pós-Graduação em Educação da Universidade Estadual de Maringá (UEM), Maringá, PR. E-mail: solangefry@gmail.com

Bethânia Vernaschi de Oliveira: Graduanda em Geografia pela Universidade Estadual de Maringá (UEM). E-mail: bth.net@outlook.com

Lucilia Vernaschi de Oliveira: Doutoranda em Educação pela Universidade Estadual de Maringá (UEM). E-mail: luvernaschi@gmail.com

\section{Recebido em agosto de 2018}

Aprovado em dezembro de 2018 
